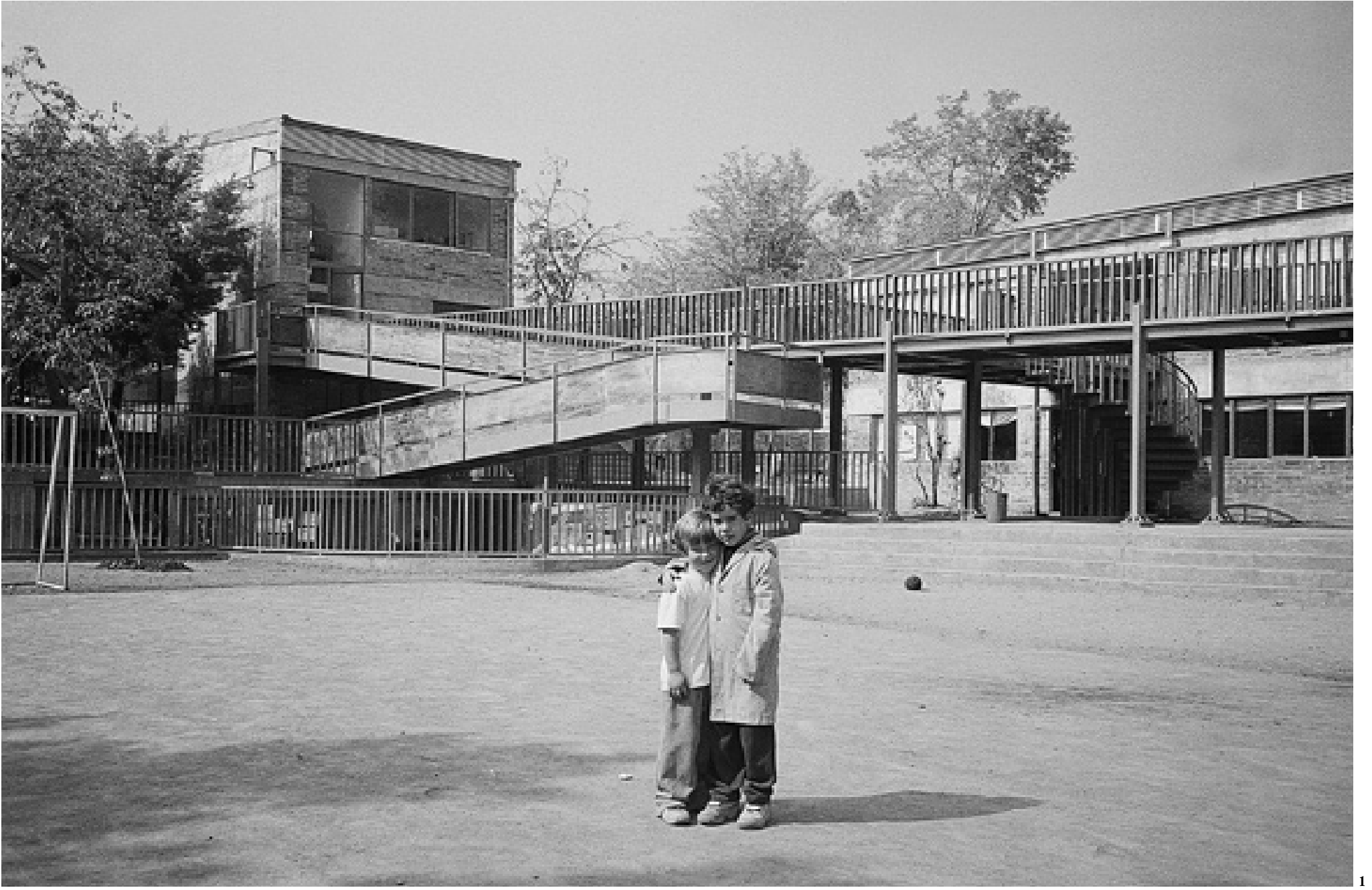

Cristián Valdés

Santiago, Chile

\section{Dos Colegios}

Economía sensible. Dos edificios construidos en lugares disímiles con treinta años de diferencia comparten cierta modestia, una escala y algunas preocupaciones: patios limitados, exteriores cubiertos, volúmenes precisos y autónomos. Se trata de proyectos cruzados por una claridad estructural que parece prever, con generosidad, cambios en el programa y las necesidades y que antes que nada provee buenos esqueletos: la escuela también puede ser el lugar de las celebraciones comunitarias, las fiestas y las asambleas. Palabras clave: Arquitectura - Chile, establecimientos educacionales, escuela rural, colegios.

Sensitive economics. Two buildings, put up on dissimilar sites, 30 years apart, share a certain bumility, a scale and some issues, like limited yards, covered exteriors, and precise, autonomous volumes. Both projects are imbued with a structural clarity that has the generosity to foresee changes of program and needs, so the school can also bouse community celebrations, parties and public meetings.

Key words: Architecture - Chile, educational institutions, rural school, schools.

\section{Colegio Altazor, La Florida}

Es un colegio nuevo de educación básica.

Nace del siguiente encargo: proyectar y construir la obra en un plazo de 6 meses, por un valor predeterminado que corresponde a un préstamo bancario. Este incluía la compra del terreno y la construcción por suma alzada de $9 \mathrm{UF} / \mathrm{m}^{2}$ construido.

El terreno para la obra, de $1.500 \mathrm{~m}^{2}$, permitía una construcción máxima de $400 \mathrm{~m}^{2}$ de acuerdo al plano regulador vigente en ese momento, que al ser modificado haría posible complementar el programa con más salas de clases y un edificio para biblioteca y cafetería en una segunda etapa.

El programa acordado para esta primera etapa consistía en 6 salas de clases con capacidad para 25 alumnos cada una, recepción y secretaría, sala de profesores y dirección, baños, espacio cubierto, patio de juegos y camarines para deportes.

El terreno tiene una diferencia de altura de 3,50 $\mathrm{m}$ entre la calle de acceso al oriente y el extremo poniente, lo que dejaba el colegio parcialmente sumergido en relación al acceso. Considerando acceso y la constructibilidad permitida en las 2 etapas posibles, se pensó en un máximo espacio libre hacia el norte, que recogiera toda la vida del colegio en un solo lugar, enmarcado por las salas de clases y la dirección.

Los pasillos de circulación habituales se pensaron como un paseo elevado que mantenía una distancia relativa que, a pesar de su presencia, permitía el asoleamiento y una mayor independencia para las salas de clases. Este puente paseo que une la dirección con las salas, junto con sus escalas y rampas trae al interior del colegio la cordillera y los árboles del sector.

El lugar bajo el puente es el espacio cubierto junto a una gradería a lo largo del patio de juegos. En un patio enterrado se instalaron los camarines para deportes, que estaban excedidos como superficie construida y no se contabilizaron por ser subterráneos. 
1 Patio central. A la izquierda, la torre de los profesores
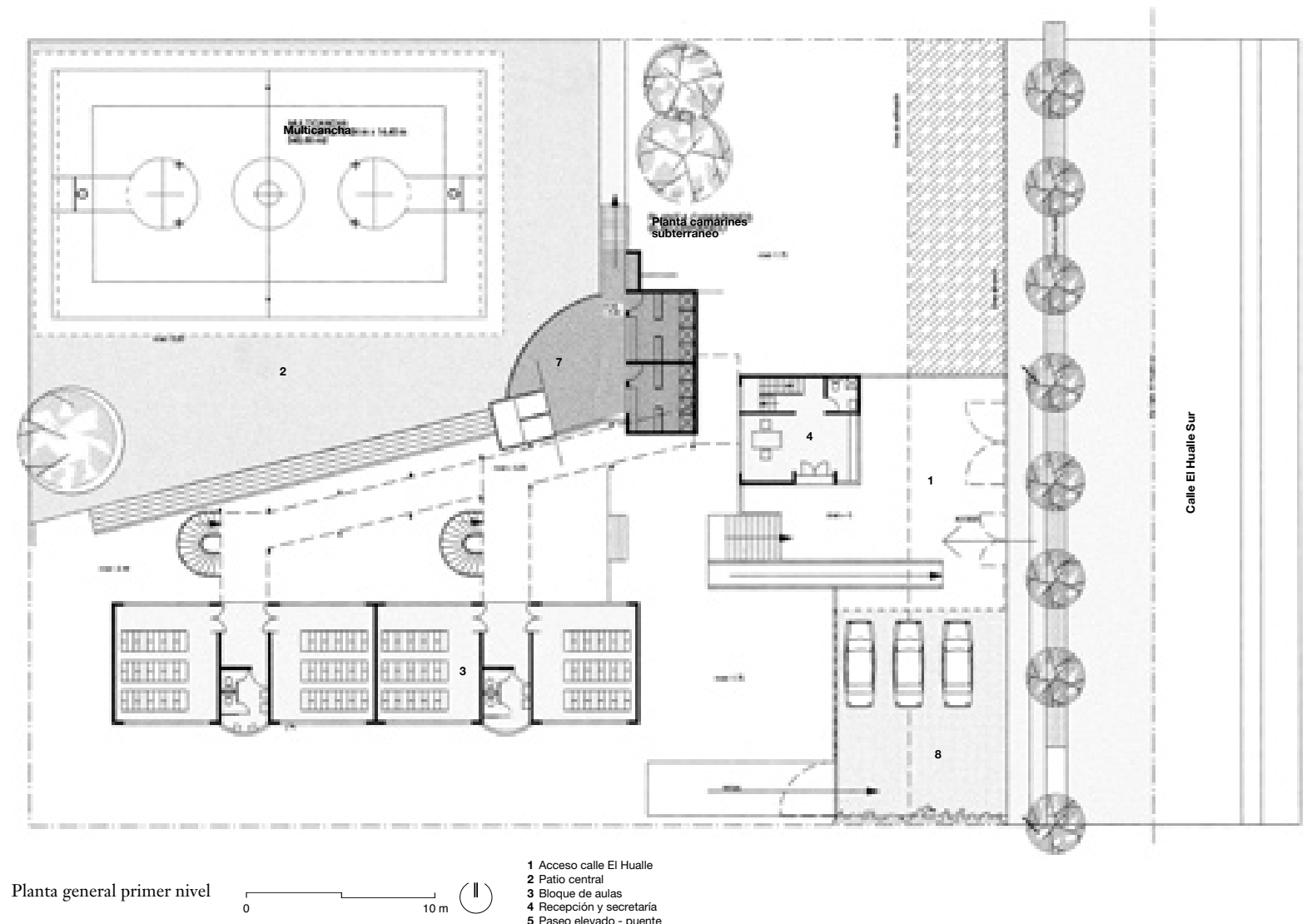

1 Acceso calle El Hualle
2 Patio central

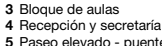

5 Paseo elevado - put
6 S Cal de proffesores
7 Emarines

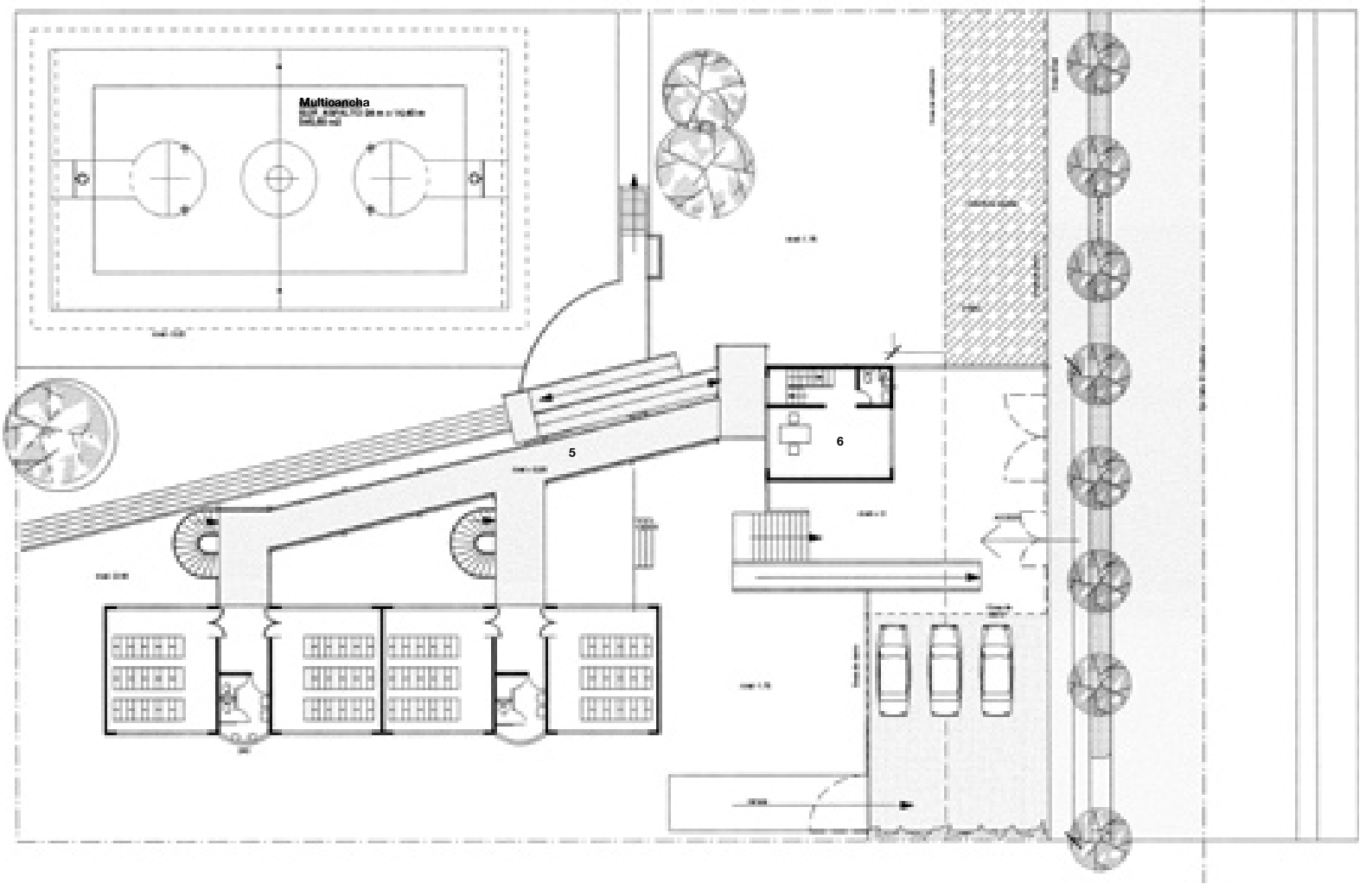

Planta segundo nivel

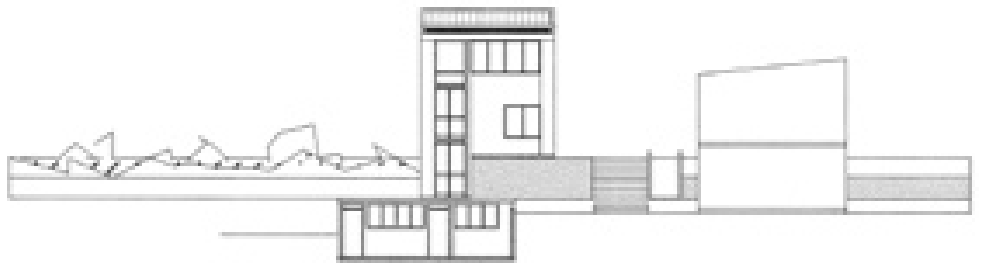

Elevación poniente, torre de los profesores

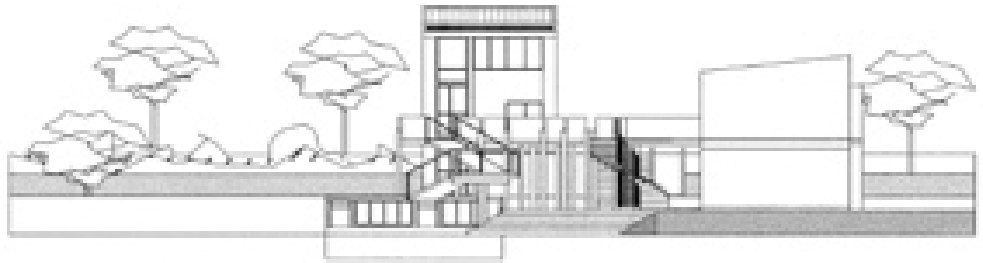

Elevación poniente, patio, puente y rampas 

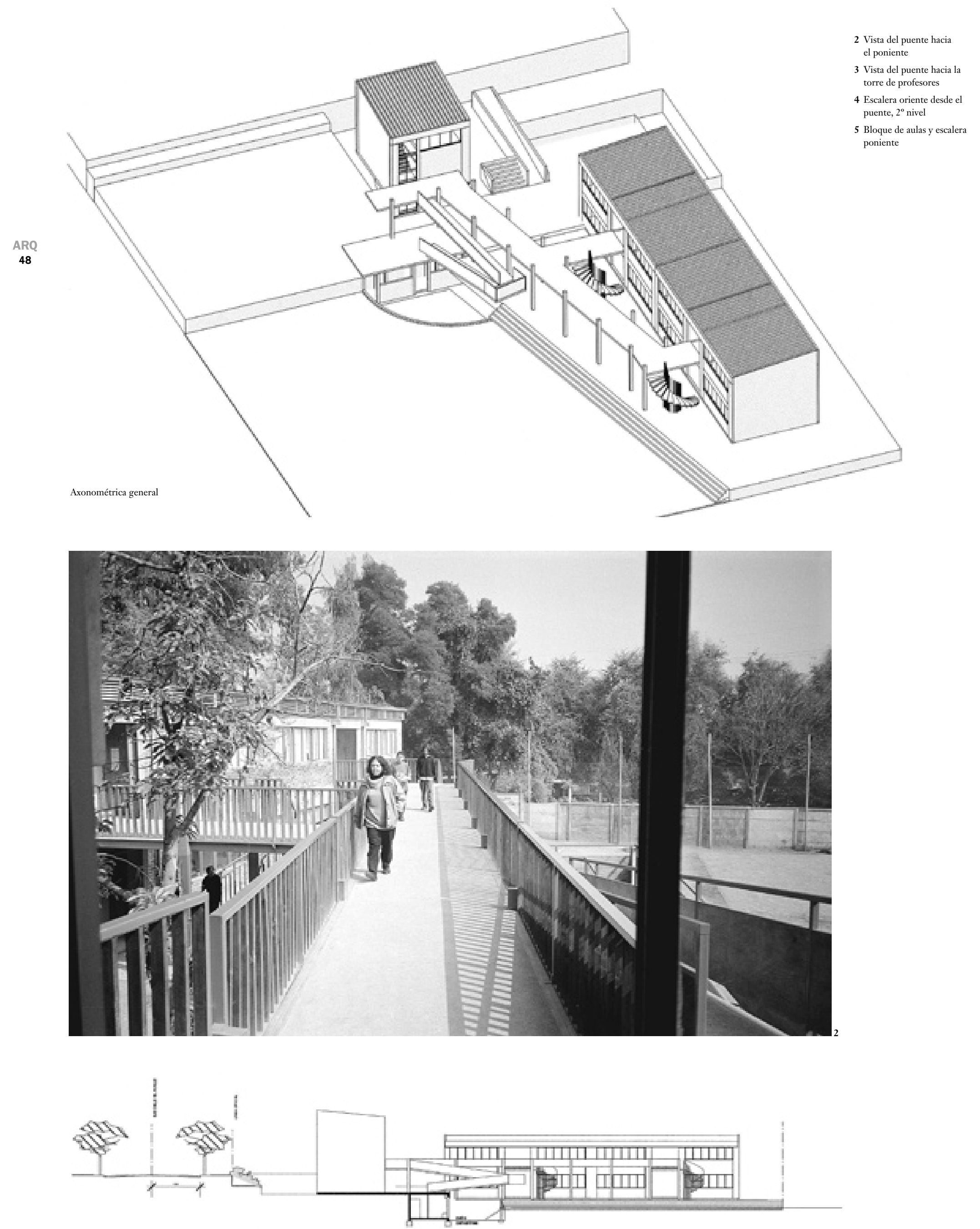

Elevación norte 

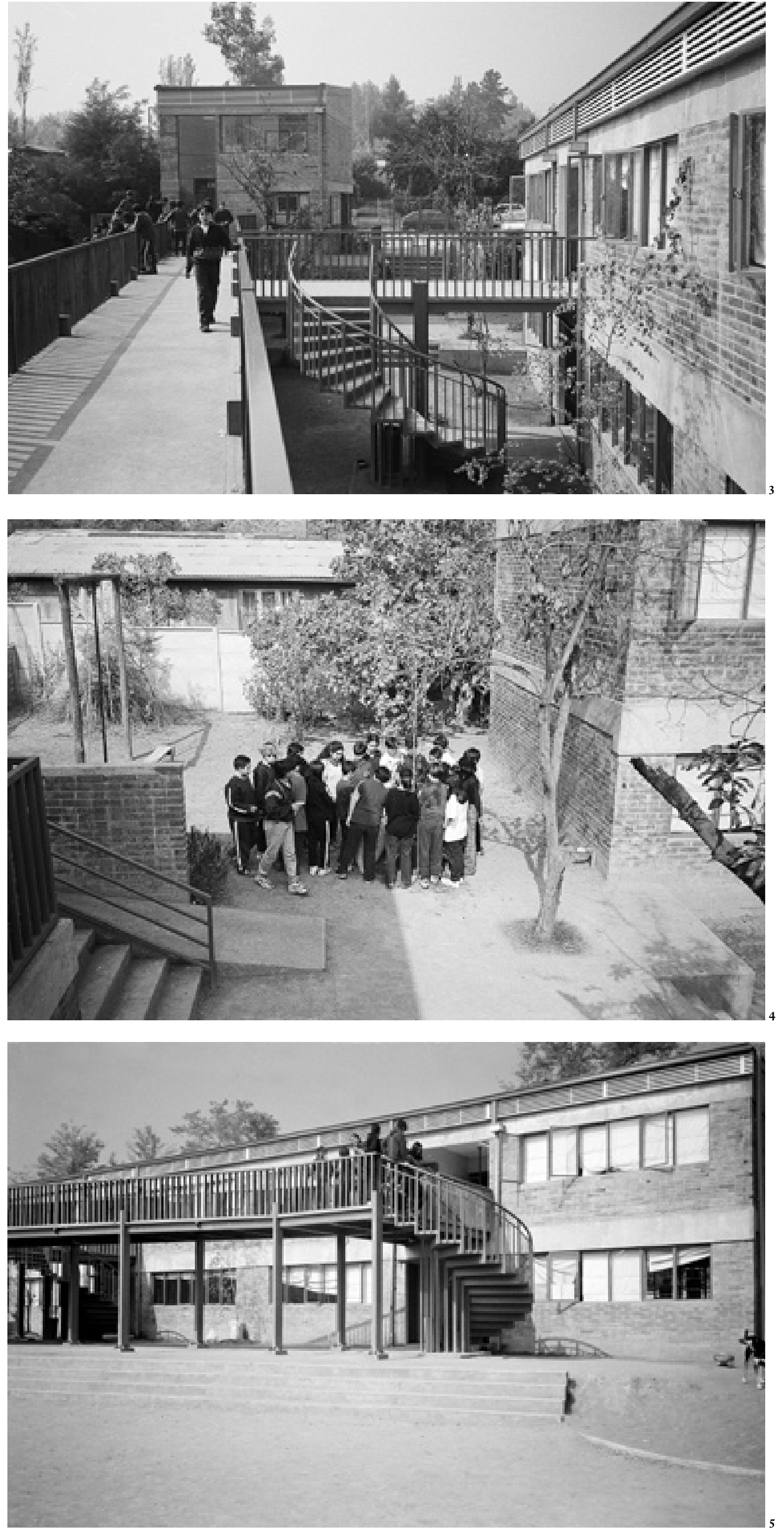

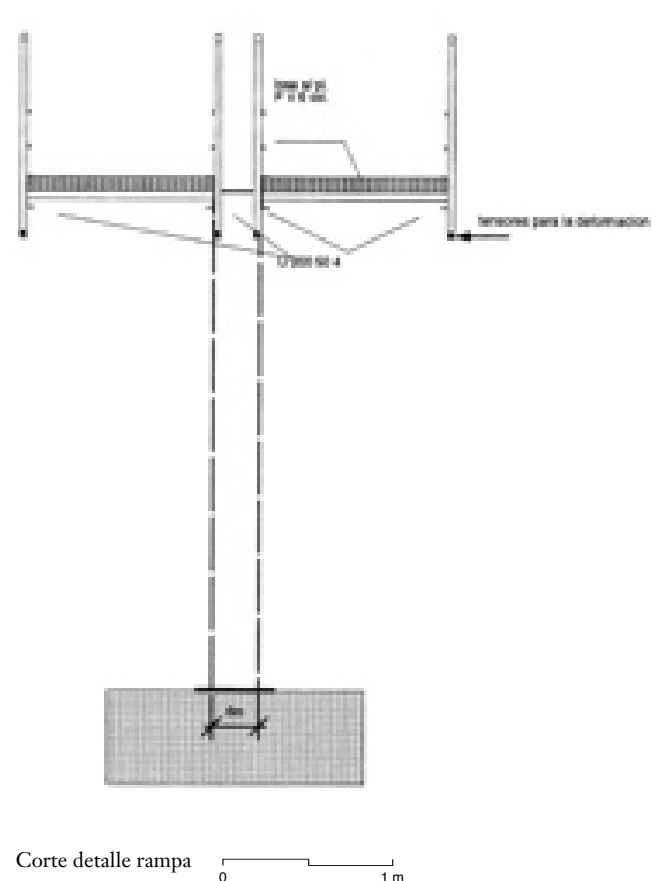

Colegio Altazor

Arquitectos Cristián Valdés y Mario Flores

Ubicación Calle El Hualle, La Florida, Santiago, Chile Cliente Sociedad educacional Altazor

Cálculo estructural Bascuñán y Maccioni ingenieros civiles y asoc. Construcción Constructora Las Torcazas

Materialidad Albañilería armada y visas de hormisón armado, cerchas de madera y cubierta metálica, puertas y ventanas en carpintería de fierro

Presupuesto de la obra $9 \mathrm{UF} / \mathrm{m}^{2}$ (US\$217/ $\mathrm{m}^{2}$ )

Superficie terreno $2.000 \mathrm{~m}^{2}$

Superficie construida $480 \mathrm{~m}^{2}$

Año proyecto 1996

Año construcción 1996

Fotografía Cristián Valdés

Imásenes digitales Cristián Valdés y Mario Flores 

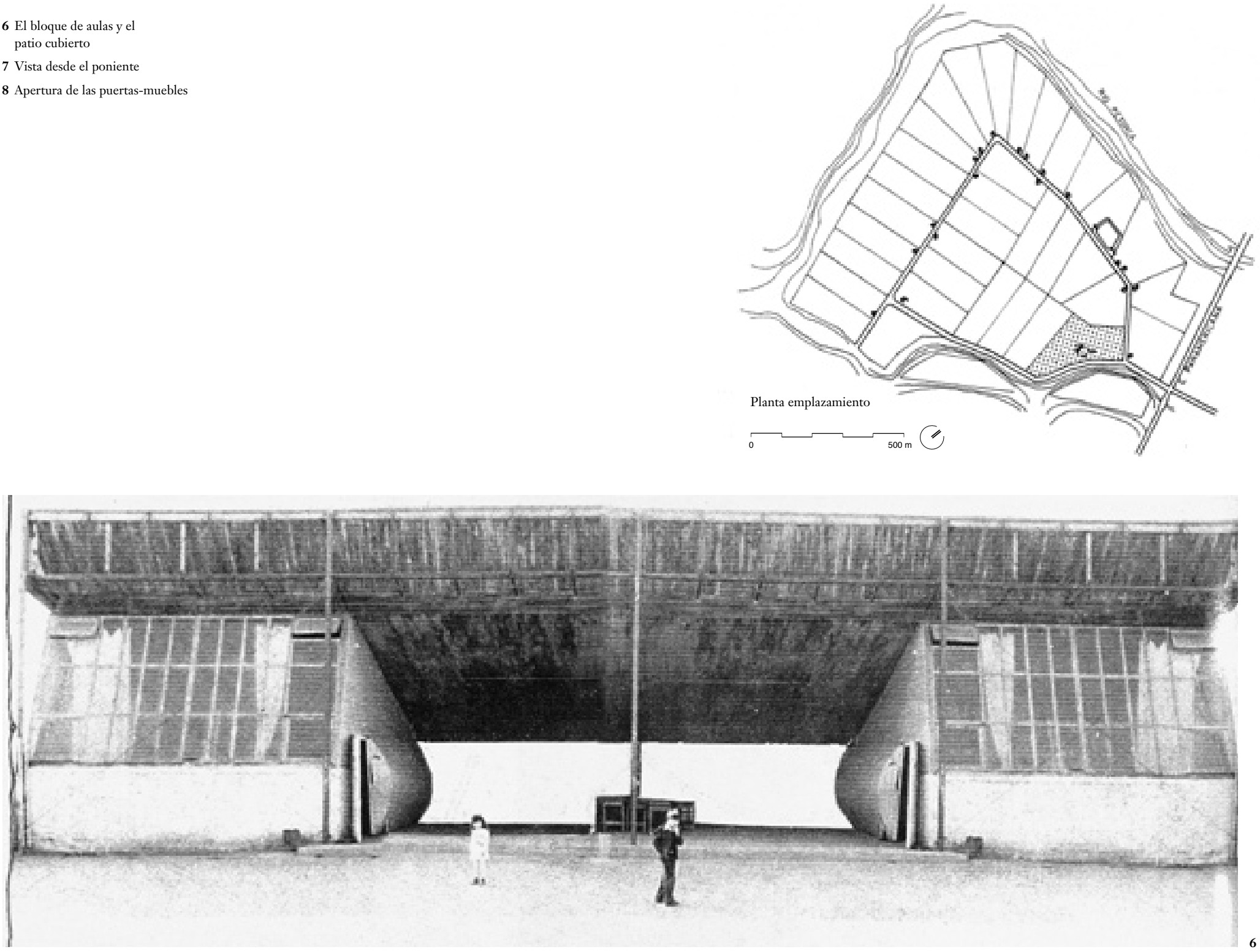

\section{Escuela rural, Longotoma}

Esta escuela es parte de un conjunto de obras en un sector del fundo San Manuel en Longotoma en el año 1963.

Se formó una cooperativa agrícola que acogía a 30 inquilinos del fundo en un sector separado por la carretera Panamericana, en huertos familiares de una hectárea cada uno en el plano, más unos faldeos de rulo en comunidad.

El encargo involucraba el proyecto y construcción de las viviendas, con un sistema flexible para acoger distintas composiciones familiares, y una escuela primaria.

La parcelación estaba hecha con anterioridad. La escuela debía tener 2 salas de clases con un corredor cubierto, casa para profesora, oficina y baños. En este contexto, en medio del campo y como único lugar de equipamiento social, la escuela se pensó como el lugar de las celebraciones y fiestas conmemorativas.

El lugar es una zona de vientos constantes de dirección noroeste; resultaba molesto para estar al exterior. Pensamos en un patio protegido del viento como un espacio de gran importancia para el lugar: el edificio de la escuela conformaba esta protección.

Una estructura principal de $24 \mathrm{~m}$ de longitud, de espaldas al viento, acoge las salas de clases y el espacio cubierto, con el techo levantado para producir una corriente de aire que pase sobre el patio dejándolo como zona de baja presión.

La estructura se dividió en 4 módulos con las salas en los extremos, dejando una gran zona cubierta que se conecta con las clases abriendo 2 puertas-muebles en $90^{\circ}$.

Con esto se obtiene una nave de $24 \mathrm{~m}$. de longitud techada, junto a un patio protegido del viento como un lugar que acoge las celebraciones locales.
El proyecto se realizó con una especificación mínima: marcos metálicos para la estructura principal anclados en poyos de hormigón, cadena superficial de hormigón por todos los bordes de la construcción, radier confinado por la cadena, y muros de albañilería sin estucar de $15 \mathrm{~cm}$, sin pilares y auto-soportantes, formando escuadras hasta una altura de $1.50 \mathrm{~m}$ con un chorizo de hormigón como remate superior. Entre la albañilería y la techumbre, tabiques de pino de 4" entablados por ambas caras con pino machihembrado; la cubierta es de planchas Pizarreño. Las puertas-muebles son de pino; su forma abombada es un intento por transformarla en una viga semi cilíndrica, haciendo trabajar las superficies entabladas. Además sirve como un clóset. El giro se apoya en rodamientos de tractor en desuso y el otro extremo en ruedas metálicas de 20 cm con llantas de goma dura. ARQ 

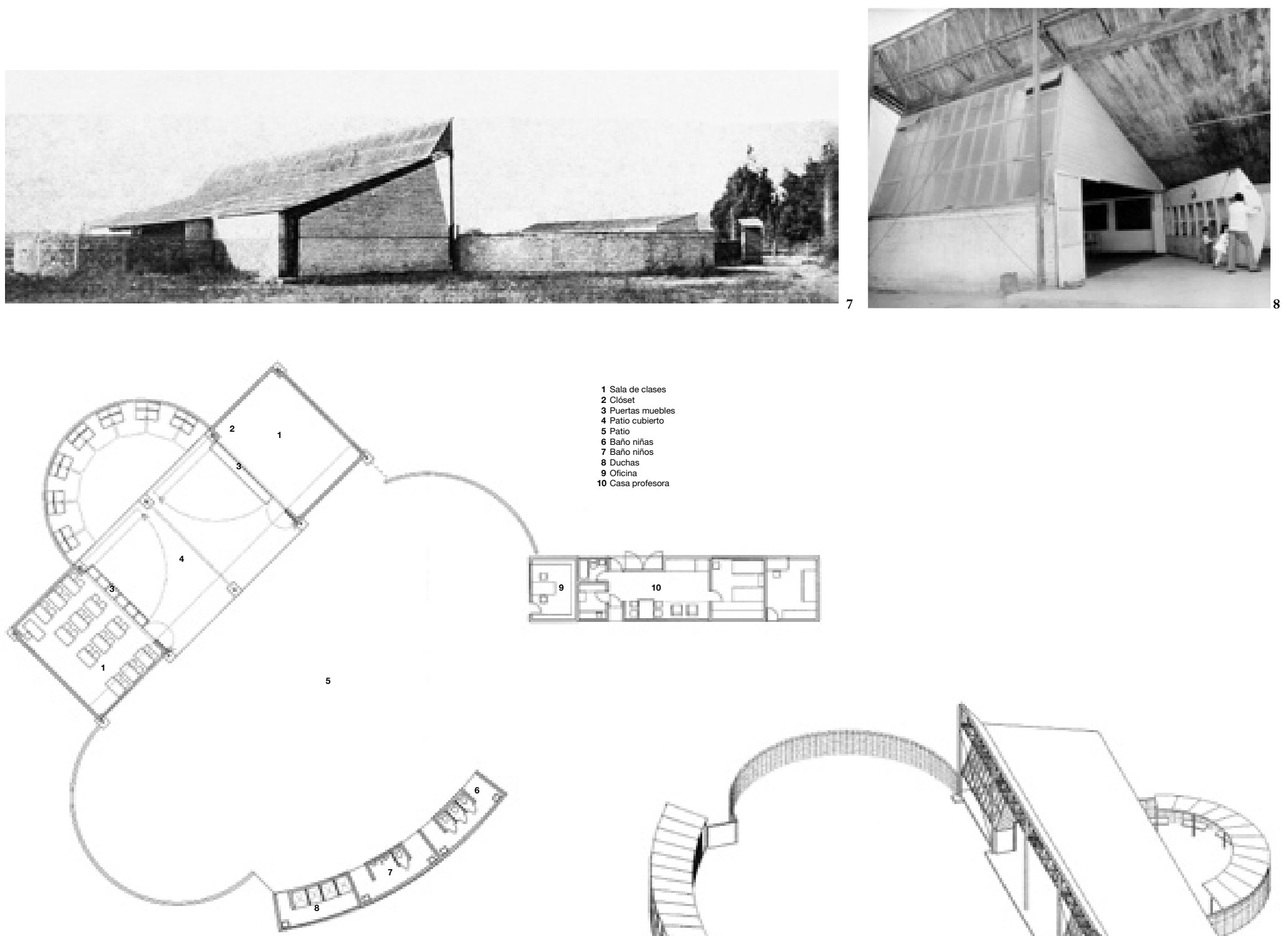

Planta general
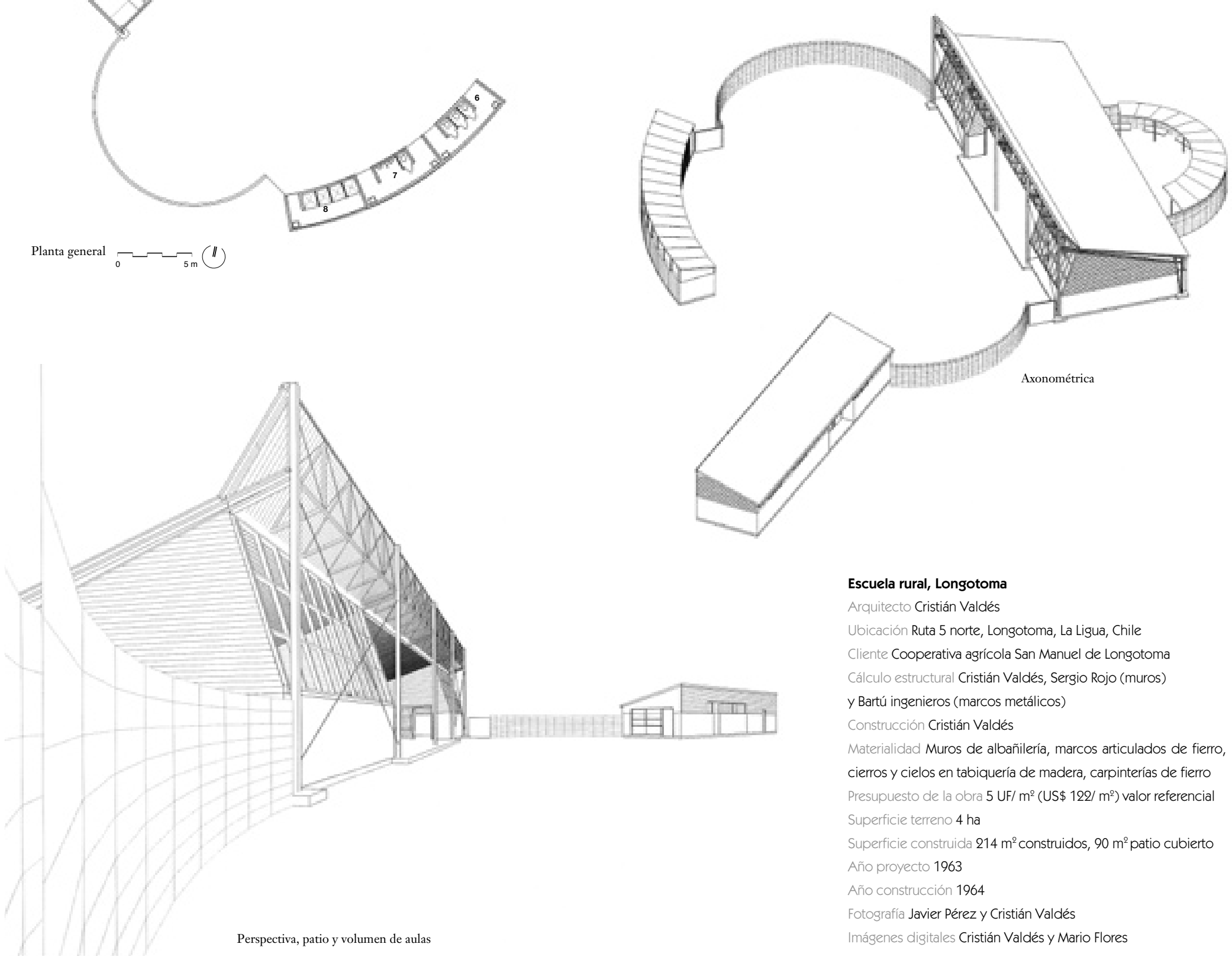

Construcción Cristián Valdés

Materialidad Muros de albañilería, marcos articulados de fierro, cierros y cielos en tabiquería de madera, carpinterías de fierro Presupuesto de la obra 5 UF/ $\mathrm{m}^{2}$ (US $\$ 122 / \mathrm{m}^{2}$ ) valor referencial Superficie terreno 4 ha

Superficie construida $214 \mathrm{~m}^{2}$ construidos, $90 \mathrm{~m}^{2}$ patio cubierto Año proyecto 1963 